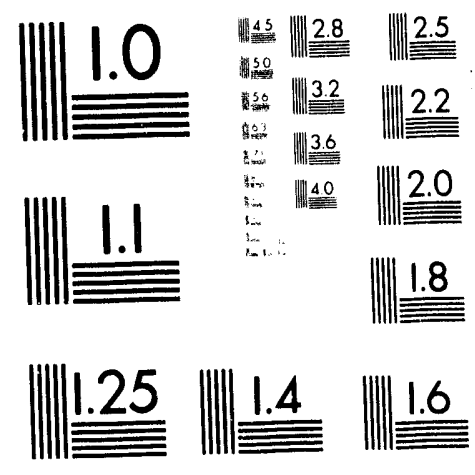



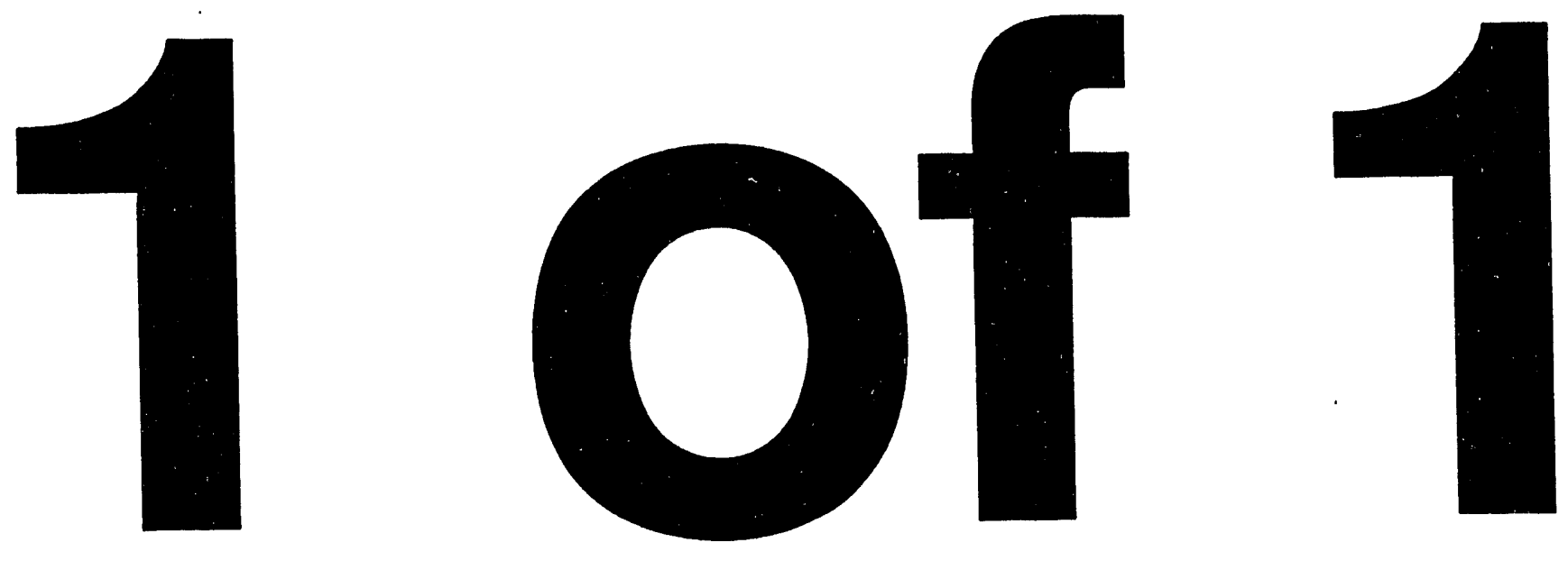


\title{
THE REACTIVITY OF LITHIUM TOWARD
} NON-AQUEOUS SOLVENTS OF RELEVANCE TO

\author{
ENERGY STORAGE APPLICATIONS
}

\section{AS STUDIED BY SURFACE ANALYTICAL TECHNIQUES}

Final Report

June 1993

by

\author{
K. Wang \\ G.S. Chottiner \\ D.A. Scherson \\ Department of Chemistry \\ Case Western Reserve University \\ Cleveland, Ohio 44106-7078
}

for
Energy \& Environment Division
Lawrence Berkeley Laboratory
Berkeley, Califurnia 94720

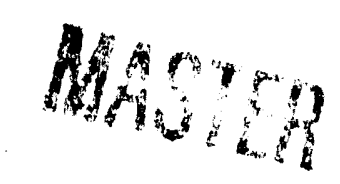

This work was supported by the Assistant Secretary for Conservation and Renewable Energy, Office of Transportation Technologies, Electric and Hybrid Propulsion Division of the U.S. Department of Energy under Contract No: DE-AC03-76SF00098, Subcontract No. 4563910 with the Lawrence Berkeley Laboratory. 
THE REACTIVITY OF LITHIUM TOWARD NON-AQUEOUS SOLVENTS OF RELEVANCE TO ENERGY STORAGE APPLICATIONS AS STUDIED BY SURFACE ANALYTICAI TECHNIQUES

\author{
K. Wang and G. S. Chottiner \\ Department of Physics \\ Daniel A. Scherson \\ Department of Chemistry \\ Case Western Reserve University \\ Cleveland, OHIO 44106
}

\title{
ABSTRACT
}

The interactions between metallic lithium and perdeuterated tetrahydrofuran (TDF) have been examined in ultrahigh vacuum (UNV) by $X$-ray photoelectron and Auger electron spectroscopies (XPS and AES, respectively) and temperature programmed desorption (TPD). The AES, XPS and TPD spectra of thick layers of $L_{i}$ vapor deposited on clean polycrystalline silver $(\mathrm{Ag}(\mathrm{poly}))$ foils exposed to up to $100 \mathrm{~L}$ TDF at room temperature showed no evidence for features other than those associated with clean $\mathrm{Li} / \mathrm{Ag}$ (poly) surfaces. This indicates that the sticking coefficient of (gaseous) TDF on Li at $\mathrm{ca} .300 \mathrm{~K}$ is negligibly small. Clearly defined $\mathrm{C}(1 \mathrm{~s})$ and $O$ (ls) XPS features were observed, however, for submonolayer coverages of TDF $(\theta$ (TIF) < 1) on $\mathrm{Li} / \mathrm{Ag}($ poly), obtained by first condensing a thick layer of TDF below $140 \mathrm{~K}$ and later gently warming the specimen to $\mathrm{ca} .300 \mathrm{~K}$. The binding energies of these peaks were smaller than those observed for condensed TDF recorded at $\mathrm{ca} .135 \mathrm{~K}$, for which the features were identical to those found for $\theta(T D F)<1$ on bare $\mathrm{Ag}($ poly) at the same temperature.

The m/e -48 TPD spectra of TDF condensed on $\mathrm{Ag}$ (poly) yielded for $\theta(T D F)<1$ a well defined peak centered in the range of $210-240 \mathrm{~K}$, a temperature much higher than that associated with the desorption of bulklike TDF (ca. $170 \mathrm{~K}$ ). Very similar results were obtained for experinents involving $\mathrm{Li} / \mathrm{Ag}$ (poly) surfaces, except that the $\mathrm{m} / \mathrm{e}-48$ peak was brciader and slightly shifted to higher temperatures. The fragmentation patterns of adsorbed TDF (either on $\mathrm{Ag}$ (poly) or $\mathrm{Li} / \mathrm{Ag}($ poly)) were consistent with cyclopropane and formaldehyde as the most likely thermally desorbed species. Unlike the behavior observed for $T D F / A g$ (poly) for which no TPD features were detected for $\mathrm{T}>300 \mathrm{~K}$, the $\mathrm{m} / \mathrm{e}-4$ TPD spectra for TDF/Li/Ag(foly) displayed a prominent peak centered at about $600 \mathrm{~K}$ attributed $t \mathrm{c}_{1} \mathrm{D}_{2}$ generated by the thermal decomposition of LiD. This provides rather unambiguous evidence that (condensed) TDF reacts with $\mathrm{Li}$ at temperatures lower than ca. $350 \mathrm{~K}$ to yield LiD as the main product. 


\section{INTRODUCTION}

Lithium is expected to find widespread use in high-energy-density batteries because of its very negative standard reduction potential and light equivalent weight. The operation of lithium electrodes in this application relies on the presence of a surface film that protects the underlying metal from further corrosion and at the same time provides a medium that can sustain facile lithium-ion transport. 1 This film forms spontaneously upon exposing air oxidized (or bare) Li surfaces to the electrolyte and is believed to contain decomposition products origineting from both the solvent and the salt (in addition to those derived from atmospheric gases). ${ }^{2}$ Technological advances over the past decade have $l \in d$ to the commercialization of primary lithium-based batteries, for which the electrochemical reaction at the anode is $\mathrm{Li}$ dissolution. Attempts to reverse the process (by using, for example, an external source to charge) and thus reconstitute the metal electrode, have met with only limited success in the sense that the amount of metal recovered is always less than that origirally dissolved. This low coulombic efficiency represents perhaps the single most serious obstacle to the development of efficient lithium-based rechargeable batteries. Most of these problems appear to stem from changes in the morphology of the metal induced by dissolution (discharge) and deposition (charging) cycles. There exists considerable evidence, for example, that under certain conditions dendrites or other types of fibrillar deposits are formed during deposition which penetrate through the protective layer and react with the electrolyte. This process brings about drastic losses in charging capacity by two different, albeit related mechanisms. Specifically,

1) the generation of electrochemically stable materials consumes progressively and irreversibly metallic lithium and 
ii) the cross section of the dendrites may reach dimensions comparable to the thickness of the passive film. Such conditions would promote the encapsulation of segments of the metal deposits within the electronically insulating layer, isolating useful material from the actual electrode.

Based on these considerations, it becomes crucial to examine the physicochemical nature of the film in terms of its structure and composition to gain a more detailed understanding of the factors that control this undesirable phenomenon. Over the past decade, various ex situ ${ }^{3-9}$ and, more recently, in situ spectroscopic techniques, $10-12$ have been employed to obtain information regarding some of these issues. Despite these efforts, a number of fundamental questions still remain to be elucidated, including, the intrinsic reactivity of lithium towards the electrolyte, particularly the solvent, and the role impurities may play in conferring upon the film its unique characteristics.

This work will examine the interactions between metallic lithium, vapor deposited on clean polycrystalline silver ( $\mathrm{Ag}(\mathrm{poly})$ ), and condensed leyers of perdeuterated tetrahydrofuran, denoted as TDF, in ultrahigh vacuum (UHV) using Auger electron and X-ray photoelectron spectroscopies (AES and XPS, respectively), and temperature programmed desorption (TPD). Silver was chosen as a substrate because of its relative inertness and the ease by which clean surfaces can be prepared. The results have shown that (condensed) TDF interacts with both bare and $\mathrm{Li}$-covered $\mathrm{Ag}$ (poly) to yield (TDF-derived) TPD features with peak temperatures much higher than those associated with its bulk desorption. In the case of Li-covered surfaces, however, the $m / e=4 \mathrm{TPD}$ revealed the presence of a peak at $600 \mathrm{~K}$, a temperature within the range in which bulk LiH (and hence LiD) has been 
reported to undergo thermal decomposition. These observations are consistent with a Li-mediated dehydrogenation of TDF to generate LiD as one of the predominant reaction products.

\section{EXPERIMENTAL}

All measurements were conducted in two independent UHV chambers. The system used for AES and TPD has been described in earlier papers. 13-14 AES spectra were recorded in a derivative mode with a beam voltage of $3 \mathrm{kV}$, a beam current of $5 \mu \mathrm{A}$ and a beam diameter of 1 to $1.5 \mathrm{~mm}$. The XPS experiments were carried out in a custom designed, multi-technique Perkin-Elmer system at a base pressure of ca. $2 \cdot 10^{-10}$ torr, equipped with an $\mathrm{Al} / \mathrm{Mg}$ dual $\mathrm{X}$-ray source and a Perkin-Elmer 10-360 hemispherical energy analyzer. All XPS multiplex spectra were collected at a pass energy of $35.75 \mathrm{eV}$ using the $\mathrm{Mg}$ anode operating at $400 \mathrm{~W}$. The data analysis was performed using a PerkinElmer 5000 series software package. Peak positions and areas were deternined by curve fitting the spectral features with asymmetric Gaussian-Lorenztians. Energies were calibrated with a $\mathrm{Au}-\mathrm{Ag}-\mathrm{Cu}$ standard built into the semple holder.

Two types of $\mathrm{Ag}$ (poly) specimens were used for these experinents depending on the specific arrangement involved in the TPD measurements: a circular foil with a cross sectional area of $0.8 \mathrm{~cm}^{2}$ mounted on a transferable sample holder of the type described by Chottiner et al.15 for electron bombardment from the rear, and a square foil of $1.2 \mathrm{~cm}$ side aifixed to a special, non-transferable holder, for resistive heating.

The $A g(p o l y)$ substrates were cleaned by a series of $\mathrm{Ar}^{+}$ bombardment/thermal annealing cycles using either one of the two hecting arrangements. Considerable care is required to detect carbon and oxygen on Ag surfaces with AES because of the overlap of the silver feature:s at $260 / 266$ and $503 \mathrm{ev}^{16,17}$ with those of carbon and oxygen at 272 and $507 \mathrm{eV}$, 
respectively. One common way of estimating the amount of carbon (on $\mathrm{Ag}$ ) relies on the measurement of the ratio $(\mathrm{Ag} 260+\mathrm{C} 270) / \mathrm{Ag} 300,18$ where the symbols represent the amplitude of the elemental AES features at the prescribed energy. In practice, $\mathrm{Ag} 260+\mathrm{C} 270$ is simply the amplitude of the (non-resolved) peak in that spectral region. The magnitude of this ratio for nominally clean silver, evaluated from several independent experiments, was found to be $0.48 \pm 0.03$, which is within the range of values (for clean silver) reported by other workers $(0.42-0.55) .18$ The corresponding oxygen ratio defined as $(\mathrm{Ag} 503+0507) / \mathrm{Ag} 351$, for which no data appear to be avallable in the literature yielded (for nominally clean silver) $0.006 \mathrm{t} / \mathrm{.}$ 0.001 .

Lithium was vapor deposited onto clean $\mathrm{Ag}$ (poly) substrates from welldegassed SAES Getters and its purity assayed with AES and XPS. After each Li source was calibrated, AES or XPS spectra of the Li/Ag substrates were not generally acquired to minimize the risk of contamination with adventitious gases in the chamber. The coverage of $\mathrm{Li}$ is reported in terms of the percent of AES signal, defined as $8 L i=I_{L i 52} /\left(I_{L 152}+I_{A g 351}\right) \times 100$, where $I_{i}$ is the amplitude of AES signal associated with the ith elemental fecture normalized by the corresponding sensitivity factor. 19 The use of thick Li overlayers is necessary since the main thrust of this work focuses on the nature of the reaction between bulk Li and TDF. Serendipitously, this avoids the problems associated with the much smaller AES and XPS sensitivity factors for $\mathrm{Li}$ compared with those of $\mathrm{Ag}$, and with the overlap of the two weak AES Ag features at 50 and $80 \mathrm{eV}^{19}$ with the Li KVV transition at $52 \mathrm{eV}$ and $\mathrm{Li}$ doubly-ionized peaks at $80 \mathrm{eV}, 20-23$ and the overlap of the XPS spectral feature of clean $\mathrm{Ag}(4 \mathrm{p})$ at $58 \mathrm{eV}$ with the $\mathrm{Li}(1 \mathrm{~s})$ peak at 54.7 eV 6,8 In addition, such high $\mathrm{Li}$ coverages are expected to reduce to a 
large extent effects associated with the possible formation of Li/Ag alloys. Perdeuterated THF (TDF, $C_{4} D_{8} O$, mass - $80 \mathrm{amu}$ ) obtained from Icon Ciorp. was used for all TPD measurements to distinguish hydrogen in THF from that due to other sources (hydrogen is the mejor background gas in UHV atmospheres). For the TPD measurements, TDF was admitted into the chamber via a doser incorporating a capacitance manometer and a multicapillary array facing the sample. Before acquisition of a set of TPD spectra (generally carried out during the same day), both the doser and the UHV chamber were repeatedly flushed with TDF (in order to desorb $C O$ and other gases fror the chamber walls) until a stable TDF mass spectrum was obtained. The reletive abundance of the fragments observed in the stable mass spectra was assumed to be characteristic of clean TDF and regarded as a reference standard for the TPD studies. The amount of condensed TDF estimated from the integrated area under the $m / e=48$ TPD peak was not found to be a linear function of the exposure. This does not represent a serious limitation as the conclusions drawn from this study do not rely on a precise knowledge of absolute coverages.

Optimized TPD curves were recorded for the most prominent fieaks identified from a survey of $\mathrm{m} / \mathrm{e}$ values in the range of 1 - 100, 1.e., $\mathrm{d} / \mathrm{e}=$ $80,78,48,46$ and 30 (TDF fragments). Also collected were spectra for $\mathrm{a} / \mathrm{e}$ $4\left(D_{2}\right)$, and $m / e=44,32,28,20$ and 18 , to identify the possible formetion of carbonate and hydroxide species arising from reactions involving $\mathrm{Li}$ and adventitious gases in the chamber such as oxygen and water.

RESULTS AND DISCUSSION

\section{A. Spectroscopic Analysis of Lithium Deposits}

The AES spectrum of a vapor-deposited $\mathrm{Li}$ layer on clean $\mathrm{Ag}$ (poly) at a coverage of 948 is shown in Fig. 1. In agreement with data reported in the literature, 20-23 this spectrum displays a prominent peak at $52 \mathrm{eV}$ that is 
characteristic of the Li KVV transition, with no evidence of carbon, oxygen or nitrogen contamination. It may be noted that the presence of the lithium overlayer brings about large distortions in the shape of the silver AES peaks. Additional support for the cleanliness of the deposits was obtained from XPS (see Fig. 2), for which the Li(1s) binding energy was found to be $54.9 \mathrm{eV}$. This value is also in accordance with that obtained by cther workers 6,8

\section{B. Spectroscopic Analysis of Condensed TDF Multilayers}

1. AES, XPS, TPD and the Effect of Electron-, and X-ray-Beam Damage Bare or Li covered $\mathrm{Ag}($ poly) substrates displayed no affinity for TLF at room temperature. This was clearly evidenced by the results obtained with AES, XPS, and TPD, for which no species could be detected either on or desorbing from the surface after dosings as high as $100 \mathrm{~L}$. For this reason, the spectroscopic characterization of TDF/Ag(poly) and TDF/Li/Ag(foly) interfaces was performed by condensing TDF at ca. $135 \mathrm{~K}$ on the desired substrate.

a. AES

Exposure of thick layers of TDF (on the order of several monolayers) condensed on either $\mathrm{Ag}($ poly) or $\mathrm{LI} / \mathrm{Ag}$ (poly) surfaces to the electron beam for periods of time as short as one minute led to development of a dark spot (clearly visible with the naked eye) at the beam position. Upon raising the temperature above $300 \mathrm{~K}$, no significant amounts of cerbon could be found with AES anywhere, except in the area probed originally by the beam at $135 \mathrm{~K}$. This indicates that the layer of TDF is irreversibly damaged by the electron beam (at least for the current settings used) limiting considerably the usefulness of AES in this investigation. 
b. XPS

The $C(1 s)$ and $O(1 s)$ XPS spectra for a thick (ca. $50 \AA$ ), freshly condensed layer of TDF on $\mathrm{Ag}$ (poly) at ca. $130 \mathrm{~K}$, shown in curves $\mathrm{A}$ in the left and right panels in Fig. 3, respectively, displayed characteristic $C(1 s)$ features at 287.0 ( $C$ in $C-C$ bonds) and $288.2 \mathrm{eV}$ ( $C$ in $C-0 . C$ borids), and one oxygen peak at $534.6 \mathrm{eV}$. The relative integrated areas of these features were in good agreement with the TDF stoichiometry. Exposure of thick layers of TDF on $\mathrm{Ag}\left(\right.$ poly) to $\mathrm{Mg}-\mathrm{K}_{\alpha} \mathrm{X}$-rays at $400 \mathrm{~W}$ for 2.5 hours (while maintaining the sample at $c a, 130 \mathrm{~K}$ ), ylelded a $C(C O C) / C(C C)$ peak ratio of about 0.75 , which is much lower than that observed for a freshly condensed TDF layer (see curves B in Fig. 3). More noticeable was the shift in the XPS peak positions toward lower binding energies and the emergence of an additional spectral feature of much smaller intensity. These spectral changes are indicative of major structural modificatioris.

Perhaps the most compeling evidence for the $x-r a y$ induced decomposition of bulk layers of TDF is the fact that a substantial anount of TDF remained on the surface after the same $X$-ray irradiated specimen was warmed to room temperature (see curves C, Fig. 3). This behavior is unlike that observed for TDF films condensed on clean $A_{g}$ and not exfosed to the $\mathrm{X}$-ray beam until after the specimen had been heated to ca. $300 \mathrm{~K}$ by flowing hot $\mathrm{N}_{2}$ through the cryostat (vide infra), in which case clean $\mathrm{Ag}$ was obtained.

c. TPD

The extreme lability of TDF (and r:-merous other organic compounds as wel1) to electron-beam dnmage is also illustrated by the results of TPD experiments in which the specimens were heated using electron bombarsment from the rear. Curve A, Fig. 4, shows a typical TPD spectrum of m/e -48 (the largest of all peaks) for a TDF layer condensed at ca. $130 \mathrm{~K}$ on bare 
$A_{B}($ poly). As clearly indicated, very poorly defined features could be found above $300 \mathrm{~K}$ not only for $\mathrm{m} / \mathrm{e}-48$ but also for other $\mathrm{m} / \mathrm{e}$ velues Including $80,78,48,46$ and 30 (not shown in this Figure). Very different results were obtained for essentially identical experiments in which the temperature was raised by means of resistive heating. As shown in Curve $B$ In the same figure, the corresponding TPD (for $\mathrm{m} / \mathrm{e}-48$ and all cther fragments) showed no features at $T>300 \mathrm{~K}$.

The damage induced by electron and $\mathrm{X}$-ray beams appears to be derived from ionization processes which lead to irreversible chemical rearrangenents within the TDF layer. $24-27$ As will be shown, the effects of X-rays could be significantly reduced by decreasing the measurement time. Furthermore, and in view of the artifacts introduced by the electron bombardment from the rear arrangement, the heating of specimens in all subsequent experiments was conducted either by resistive heating or, before this was implemented, by flowing hot $\mathrm{N}_{2}$ gas into the cryostat.

2. XPS and TPD of TDF Layers Adsorbed on $A g$ and L1/Ag Substrates. XPS of TDF/L1/Ag

The $L i(1 s), O(1 s)$ and $C(1 s)$ regions obtained at ca. $300 \mathrm{~K}$, for a TDF layer which had been first condensed at ca. $130 \mathrm{~K}$ on $\mathrm{LI} / \mathrm{Ag}$ (poly) and later warmed to room temperature (using hot nitrogen) to desorb bulk-like material are shown in Figure 5. Particularly noteworthy is the fact that the $c(1 s)$ and $O(1 s)$ binding energies associated for this specimen are lower than those found for bulk TDF and, in the case of $C$, the two large features display very different integrated areas. This indicates that the interactions between TDF and the Li are strong enough to induce substantial modifications to the cyclic ether structure. This is in contrast with the behevior observed for a single monolayer of TDF adsorbed on $\mathrm{Ag}$ (poly) at $130 \mathrm{~K}$, in 
which case the XPS (recorded at that temperature) was essentially identical to bulk-like TDF, and the AES, TPD and XPS spectra obtained after raising the temperature to $300 \mathrm{~K}$ (uiling hot nitrogen) ylelded no evidence for the presence of carbon or oxygen on the surface. This lack of residual impurities offers strong proof that the damage induced by short $\mathrm{X}$-ray exposures is negligible, and therefore that the spectral changes observed in the case of the $T D F / L i / A g(p o l y)$ specimen are promoted by the 11thium overlayer. It may also be noted that the $c(1 s)$ binding energies associated with the X-ray damaged TDF layer are higher than those found for the $\mathrm{TDF} / \mathrm{Li} / \mathrm{Ag}(\mathrm{poly})$ interface.

The fact that the sticking coefficient of TDF on Li (vide supra) at ca. $300 \mathrm{~K}$ was found to be negligible points to a high activation energy for gas phase adsorption; however, once this barrier is overcome by, for exanple, forcing molecules on the surface via condensation (as was the case in these experiments), more complex pathways may be favored. Far more reverling information was obtained from the results of TPD experiments described in detailed below.

TPD

\section{TDE $/ \mathrm{Ag}$}

Before investigating the behavior of TDF on Li supported on $\mathrm{Ag}$ (paly), the affinity of TDF for bare $\mathrm{Ag}$ (poly) was examined by TPD by conderising layers of the compound at ca. $130 \mathrm{~K}$. Figure 6 shows a series of $\mathrm{m} / \mathrm{e}-4 \varepsilon$ TPD spectra obtained for TDF exposures of $5,10,15,25,50$ and $100 \mathrm{~L}$. For $5 \mathrm{~L}$, the TPD spectrum exhibited a single peak, denoted as $a$, for which the maximum temperature $\left(T_{p}\right)$ was found to shift to lower values as the coverage was increased. The area under this peak reached a limiting value for $15 \mathrm{~L}$. For higher exposures, the TPD spectra displayed a second peak, denoted $\varepsilon s \beta$, with $T_{p}=172 \pm 3 \mathrm{~K}$ independent of coverage. In contrast to peak $\alpha$, the area 
under this peak increased monotonically with exposure and became the dominant feature above $50 \mathrm{I}$.

As shown in Table I, the fragmentation pattern of peak $\beta$ was identical to that observed for gas phase TDF (see above). A similar analysis of the fragments observed for peak $\alpha$, however, revealed systematic deviations of the peak ratios with respect to those obtained for neat TDF (See Table I). These observations clearly indicate that peak $\beta$ is due to the simple sublimation of bulk-like condensed TDF, whereas peak $\alpha$ can be ascribed to TDF bound directly to the bare $\mathrm{Ag}$ (poly).

No evidence for carbon or oxygen impurities could be detected by AES after the temperature (during TPD) was raised to $850 \mathrm{~K}$, in which case the spectra yielded $(\mathrm{Ag} 260+\mathrm{C} 270) / \mathrm{Ag} 300$ and $(\mathrm{Ag} 503+0507) / \mathrm{Ag} 351$ ratios of 0.48 $+/-0.02$ and $0.006+/-0.001$, respectively, which are essentially identical to those observed for clean $\mathrm{Ag}$.

\section{TDF/Li/Ag}

The $\mathrm{m} / \mathrm{e}=48 \mathrm{TPD}$ spectra for TDF condensed at $130 \mathrm{~K}$ on $\mathrm{Ag}$ (poly) and $\mathrm{Li} / \mathrm{Ag}$ (poly) at coverages low enough for peak $\alpha$ to be the dominant fecture are shown in Curves $A$ and $B$, Figure 7 , respectively. As indicated, the width of the peak for the $\mathrm{Li} / \mathrm{Ag}$ (poly) specimen was larger than that for $\mathrm{Ag}$ (foly) with a tail extending beyond room temperature.

Both $\mathrm{Li}$ covered $\mathrm{Ag}$ (poly) and bare $\mathrm{Ag}$ (poly) yielded essentially identical ratios for $m / e=80,78,48,46,30$. However, for $\mathrm{Li} / \mathrm{Ag}$ (poly) the m/e - 28 peak for low exposures was five times larger than that observed for neat TDF. As was the case with bare $A g$ after TPD, the amount of carbon on the surface, as determined by the appropriate AES amplitude ratio (vide supra), $0.45 \pm 0.03$, was essentially negligible. In contrast, the corresponding ratio for the oxygen AES feature was slightly higher than that 
for clean Ag. This difference, however, does not appear to originate from TDF as similar values were observed for $\mathrm{LI} / \mathrm{Ag}$ surfaces after heating to 800 $K$ without prior exposure to TDF, and therefore may be attributed to a very small oxygen contamination in the entire lithium layer.

The most striking effect derived from the presence of the Ii layer on the silver surface is the appearance of a sharp $\mathrm{m} / \mathrm{e}=4 \mathrm{TPD}$ peak at $600 \mathrm{~K}$ associated with $D_{2}$ (see Curve $A$, Figure 8) not observed on bare $A g$ (fioly) (see Curve B, in the same figure). Experiments in which Li/Ag surfaces at $300 \mathrm{~K}$ were exposed to $\mathrm{H}_{2}$ (generated purposely by the titanium sublimetion pump) yielded a m/e - 2 TPD feature in the same temperature range. No such peak was observed for identical experiments involving bare $\mathrm{Ag}$ (poly) surfaces. Based on these observations and the fact that $T_{p}$ is very similar to the temperature at which LiH undergoes decomposition it can be concluded that this TPD feature corresponds to the thermal decomposition of LiD. $2 \varepsilon, 29$

Several possibilities were explored to establish on a firm basis that the LiD was indeed derived from a reaction between TDF and $\mathrm{Li}$ and not from other sources.

i) The level of $D_{2}$ in the UHV chamber (following numerous experinents involving TDF) was still within detection limits, but far too low to account for the size of the TPD feature. This was verified by recording the magnitude of the m/e - 4 TPD peak after exposing a freshly deposited $\mathrm{Li} / \mathrm{Ag}$ surfaces to background gases for times equivalent to those involved in the TDF-TPD measurements. The integrated areas in such experiments yielded values about two orders of magnitude smeller than that shown in Figure 8.

ii) The amount of $D_{2}$ during TDF dosing (as monitored by the mass spectrometer) increased well beyond that expected based on the fragmentation pattern of TDF. This phenomenon is due to the 
displacement of $D_{2}$ from surfaces in the vacuum chamber induced by the presence of TDF. Drastic reductions in the amount of background $D_{2}$ observed during TDF dosing could be achieved by first purging the chamber with TDF. However, the magnitude of the m/e -4 TPD peak for $\mathrm{Li} / \mathrm{Ag}$ surfaces exposed to TDF at ca. $130 \mathrm{~K}$ was not reduced by this procedure.

iii) As was mentioned earlier in Section B.1, TDF exhibits no affinity for Li at room temperature; therefore, if the increase in the partial pressure of TDF during a TPD experiment is sufficient to induce the desorption of $D_{2}$ from the chamber, a clearly defined $D_{2}$ peak at $600 \mathrm{~K}$ should become evident in the TPD spectra. The fact that no $D_{2}$ features could be observed after exposure of $\mathrm{Li} / \mathrm{Ag}$ (poly) to TDF at ca. $300 \mathrm{~K}$ in such experiments clearly shows that the $D$ in LiD originates from TDF and not from the other sources.

Since the amount of carbon and oxygen left on the surface after TPD was essentially negligible, and given that the possibility of $C$ and 0 diffusion into $\mathrm{Ag}$ seems unlikely, it can be concluded that TDF (THF) reacts with I.I at temperatures below ca. $350 \mathrm{~K}$ (following the trailing edge of the TPD peak associated with larger masses) to form LiD as the only reaction product left on the surface after heating to $350 \mathrm{~K}$.

Additional insight into the possible nature of the compounds generated either prior to or during LiD formation was gained by examining the neture of the desorbed products. Based on a thorough survey of the cracking pattern literature one of the most likely candidates is 1-butene-3,4-epoxy, $C_{4} D_{6} O$. This compound lacks a parent peak (m/e - 76), but displays the same major fragments found for TDF. 30 Another possibility involves the formation of $\mathrm{C}_{3} \mathrm{D}_{6}$ (mass -48 ) and $\mathrm{CD}_{2} \mathrm{O}$ (mass -32 ), for which all the fragments observed 
are in agreement with literature data. 30 The main virtue of this latter model is that $C D_{2} O$ can lose $D_{2}$ and thus account for the rather large amcints of $C O$ in the TPD spectrum. It must be stressed, however, that the preserice a m/e -80 peak in the TPD spectra of TDF at low coverages indicates that about $2 / 3$ of the TDF overlayer desorb intact from the surface.

In view of the similarities between the TPD behavior of TDF on $A g$ and $\mathrm{Li} / \mathrm{Ag}$ (see Table I) it seems conceivable that the thermal desorfition pathways on both surfaces are the same except that in the latter case deuterium reacts with $L_{i}$ to form LiD.

CONCLUSIONS

The interactions between TDF and vapor-deposited layers of metallic Li on $\mathrm{Ag}$ (poly) substrates have been investigated in UHV by AES, XPS and TPD. No differences between the AES, XPS and TPD spectra of Li/Ag(poly) could be detected before and after exposure of these surfaces to up to $100 \mathrm{~L}$ TDF at room temperature. This behavior is unlike that observed for TDF layers condensed on these surfaces, in which case all three techniques provided evidence for rather strong adsorbate/substrate interactions. In particular, the XPS spectra for TDF adsorbed on $\mathrm{Li} / \mathrm{Ag}$ (poly) at ca. $130 \mathrm{~K}$ displayed $\mathrm{C}(1 \mathrm{~s})$ and $O(1 s)$ peaks with relative areas and binding energies much different than those observed for the neat material. An analysis of the TPD spectra of this adsorbed species yielded fragments with a relative abundance inconsistent with those of neat TDF. More striking, however, was the presence of a urique m/e -4 peak at about $600 \mathrm{~K}$, a temperature at which LiH (and correspondingly LiD) is expected to undergo thermal decomposition. On the basis of these results it has been concluded that condensed TDF reacts with Li to yield at about room temperature LiD as the main reaction product. A deteiled analysis of all other mass fragments strongly suggest a mixture of cyclopropane, formaldehyde and $\mathrm{CO}$ as the most likely thermally descirbed 
products of the adsorbed, activated species generated at lower temperatures. Essentially identical experiments involving 1fthium-free Ag(poly) substrates yielded rather similar results, except that no $\mathrm{m} / \mathrm{e}-4$ peak could be detected other than that derived from the cracking of higher molecular weight species desorbed at much lower temperatures. This provides some evidence that the two substrates may share a common TDF activation pathway in the low temperature range, but that the intrinsic reactivity of lithium toward the adsorbed species, including its thermally activated derivatives determines ultimately the nature of the final products.

\section{REFERENCES}

1. Gabano, J. P., Ed., Lithium Batteries, Academic Press, New York, 1983.

2. Venkatasetty, H. V., Ed. Lithium Battery Technology, John Wiley $f$ Sons, 1.984

3. Aurbach, D.; Daroux, M. L.; Faguy, P. W.; Yeager, E. J. Electrochem. Soc., $1987,7,1611$.

4. Aurbach, D.; Daroux, M. L.; Faguy, P. W.; Yeager, E. J. Electrochem. Soc., $1988,8,1863$.

5. Zavadil, K. R.; Armstrong, N. R. Surface Science, 1990, 230, 47-60

6. Hoenigman, J. R.; Kell, R. G. Surf. Sci., 1984, 18, 207.

7. Nebesny, K. W.; Zavadil, K.; Burrow, B.; Armstrong, N. R., Surf. Sci., $1985,162,292$.

8. Zavadil, K. R.; Armstrong, N. R. Surf. Sci., 1990, 230, 61.

9. McLean, W.; Schultz, J. A.; Pedersen, L. G.; Jarnagin, R. C., Surf. Sci., $1979,83,354$

10. Goren, E.; Chusid, 0.; Aurbach, D., J. Electrochem. Soc., 1991, 138, L6.

11. Aurbach, D., J. Electrochem. Soc., 1989, 136, 1606.

12. Aurbach, D., J. Electrochem. Soc., 1989, 136, 1611. 
13. Wang, K.; Eppel1, S.; Chottiner, G. S.; Scherson, D. A. Rev. Sc1. Instru., 1993, 64, 1066.

14. Herrera-Fierro, P; Wang, K.; Wagner, F. T.; Moylan, T. E.; Chottiner, G. S.; Scherson, D. A., J. Phys. Chem., 1992, 96, 3788.

15. Chottiner, G. S.; Jennings, W. D.; Pandya, K. I. J. Vac. Sc1. Technol. 1987, A5, 2970.

16. Cardillo, M. J.; Becker, G. E.; Hamann, D. R.; Serri, J. A. ; Whitman, L.; Mattheiss, L. E., Phys. Rev. 1983, B28-2, 494.

17. Campbel1, C. T.; Paffett, M. T., Surf. Sci., 1984, 143, 517.

18. Musket, R. G.; Mclean, W.; Colmenares, C. A.; Makowiecki, D. M.; Siekhaus, W. J., Appli. Surf. Sci., 1982, 10, 143.

19. Handbook of Auger Electron Spectroscopy, Perkin-Elmer Corporation, 1978.

20. Zehner, D. M.; Clausing, R. E.; McGuire G. E.; Jenkins, L. H. Sol. State Comm. , 1973, 13, 681.

21. Jackson, A. J.; Tate, C.; Gallon, T. E.; Bassett, P. J.; Matthew, J. A. D. J. Phys, F: Metal Physics, 1975, 5, 363.

22. Schowengerdt, F. D.; Forrest, J. S. Scan. Electron Micro., 1983, 11, 543.

23. Parker, S. D. Surf. Sci., 1985, 157, 261.

24. Pantano, C. G.; Madey, T. E., App1. Surf. Sci., 1981, 7,115.

25. Akhter, S.; Allan, K.; Buchanan, D.; Cook, J. A.; Canpion, A.; White, J. M., Appl. Sur. Sci., 1988-1989, 35, 241.

26. Wheeler, D. R.; Pepper, S. V., J. Vac. Sci. Technol., 1992, 20, 226.

27. Cazaux, J., Appl. Surf. Sci., 1985, 20, 457.

28. Powe11, G. L.; McGuire, G. E.; Easton, D. S.; Clausing, R. E. Surf. Sci., 1974, 46, 345 .

29. Holcombe, C. E., Jr.; Powe11, G. L.; Clausing, R. E. Surf. Sci., 1972, $30,561$. 
30. Index of Mass Spectral Data, AMD11, 1969, American Society for Testing and Materials.

FIGURE CAPTIONS

Figure 1. AES spectrum of a vapor deposited li layer (948) on clean Ag(poly) at $130 \mathrm{~K}$.

Figure 2. Li(1s) XPS spectrum for a lithium film deposited at $130 \mathrm{~K}$.

Figure 3. $C(1 s)$ (Left Panel), and $O(1 s)$ (Right Panel) XPS spectra for a freshly condensed layer of TDF (ca. $50 \AA$ thick) on $\mathrm{Ag}$ (poly) at 130 $K$ before (Curves $A$ ) and after (Curves B) exposure to $X$-ray radiation from a $\mathrm{Mg}$ source for 2.5 hours. Curves $\mathrm{C}$ in these Panels show the corresponding XPS spectra obtained for the X-ray exposed specimen after it had been warmed up to room temperature using, hot nitrogen.

Figure 4. Comparison between TPD ( $m / e-48)$ spectra for TDF condensed at 130 $\mathrm{K}$ on a Li-covered $\mathrm{Ag}(\mathrm{poly})$ surface obtained with electron bombardment from the rear (Curve $A$ ) and resistive heating (Cirve B). Heating Rate: $5 \mathrm{~K} / \mathrm{s}$.

Figure 5. $L i(1 s), C(1 s)$ and $O(1 s)$ XPS regions obtained on clean L1 (Curve A) and after adsorption and subsequent desorption (using hot nitrogen) of condensed layers of TDF (ca. $50 \mathrm{~L}$ ) at $130 \mathrm{~K}$ (Curve B).

Figure 6. Series of TPD $m / e-48$ spectra obtained for TDF at the specifled exposure. Heating Rate: $5 \mathrm{~K} / \mathrm{s}$.

Figure 7. TPD (m/e - 48) spectra for TDF condensed at $130 \mathrm{~K}$ on bare $\mathrm{Ag}(\mathrm{f} 0 \mathrm{ly})$ (Curve A) and $\mathrm{Li}$-covered $\mathrm{Ag}($ poly) (Curve B). Heating Rate: $5 \mathrm{~K} . / \mathrm{s}$. Figure 8. TPD ( $\mathrm{m} / \mathrm{e}-4)$ spectra of TDF condensed at $130 \mathrm{~K}$ on Li-covered $\mathrm{Ag}($ poly) (Curve $A$ ) and on $\mathrm{Ag}($ poly) (Curve B). Heating Rate: $5 \mathrm{k} / \mathrm{s}$. 
TABLE I

\begin{abstract}
Temperature Programmed Desorption Peak Areas Normal1zed
by the Area of $\mathrm{m} / \mathrm{e}-48$ for $\mathrm{HIgh}^{+}$and $\mathrm{LOw}^{+}$

Exposure of TDF to $A g(p o l y)$ and $L 1$-covered $A g$ (poly)
\end{abstract}

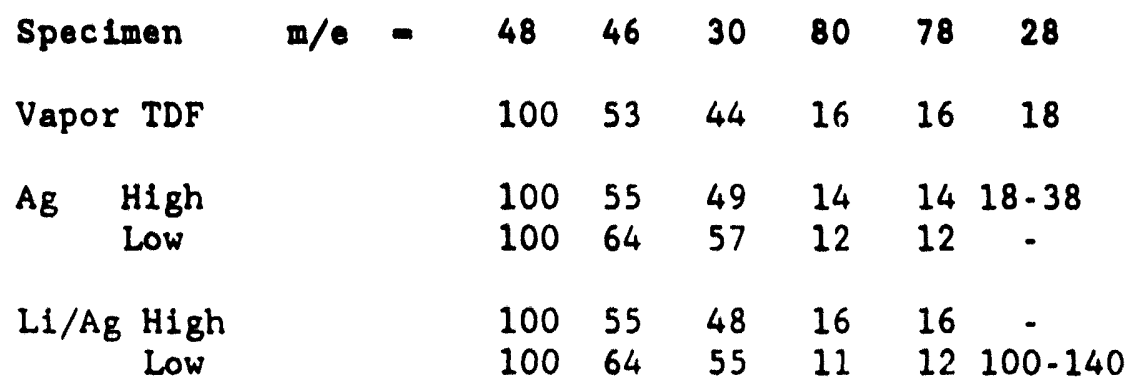

+ High and low in this context refer to TDF exposures for which the TPD spectra was dominated by the low $(\beta)$ and high $(\alpha)$ temperature features, respectively. The uncertainties in the magnitude of the fragment ratios derived from a statistical analysis of the results of many independent measurements does not exceed 78 for all species, e.g. for $\mathrm{Ag}$ at $\mathrm{high}$ exposure, $m / e-30 \pm 1$, except for $m / e-28$, for which the error was much greater (ca. 50 \&). 


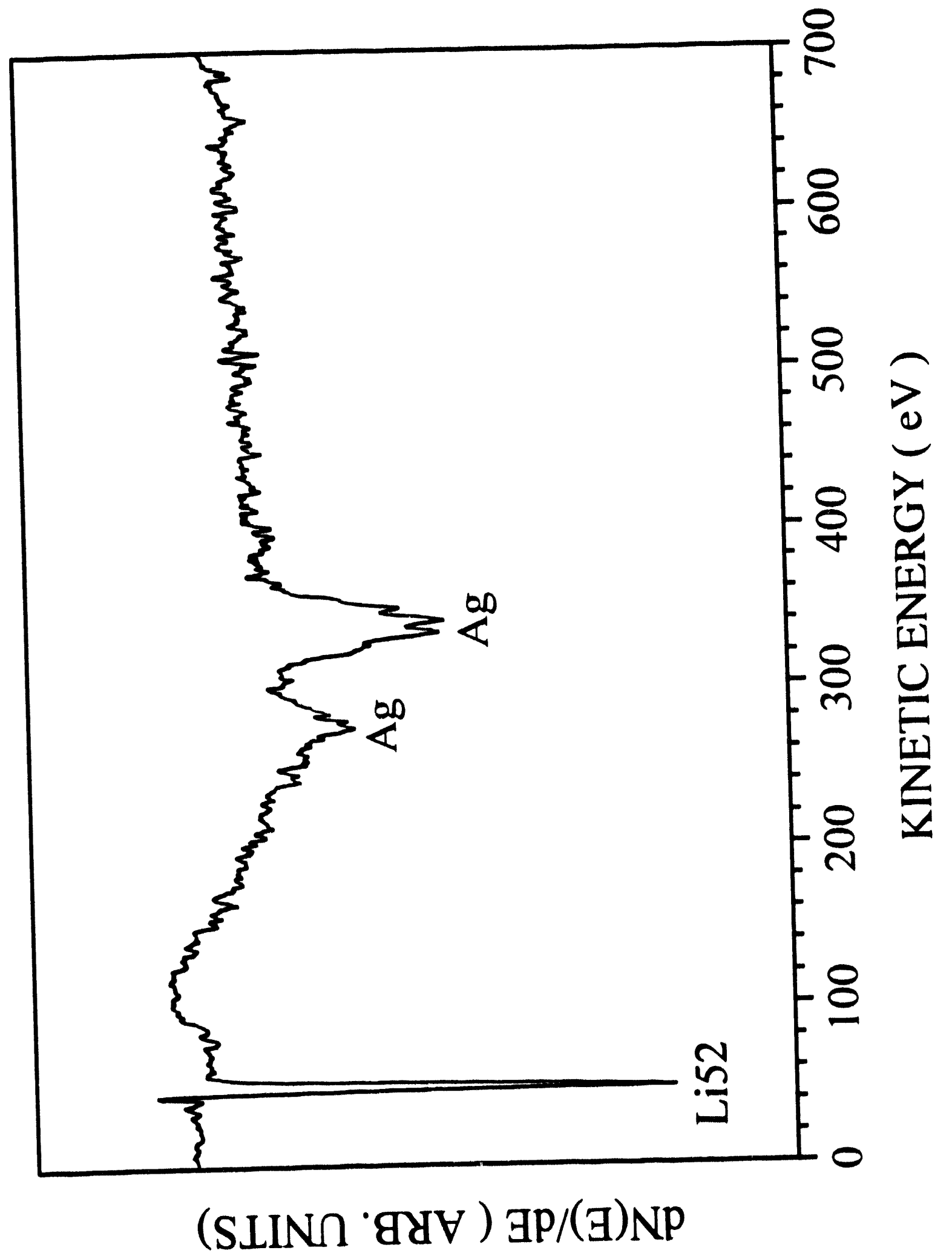

Figure 1 


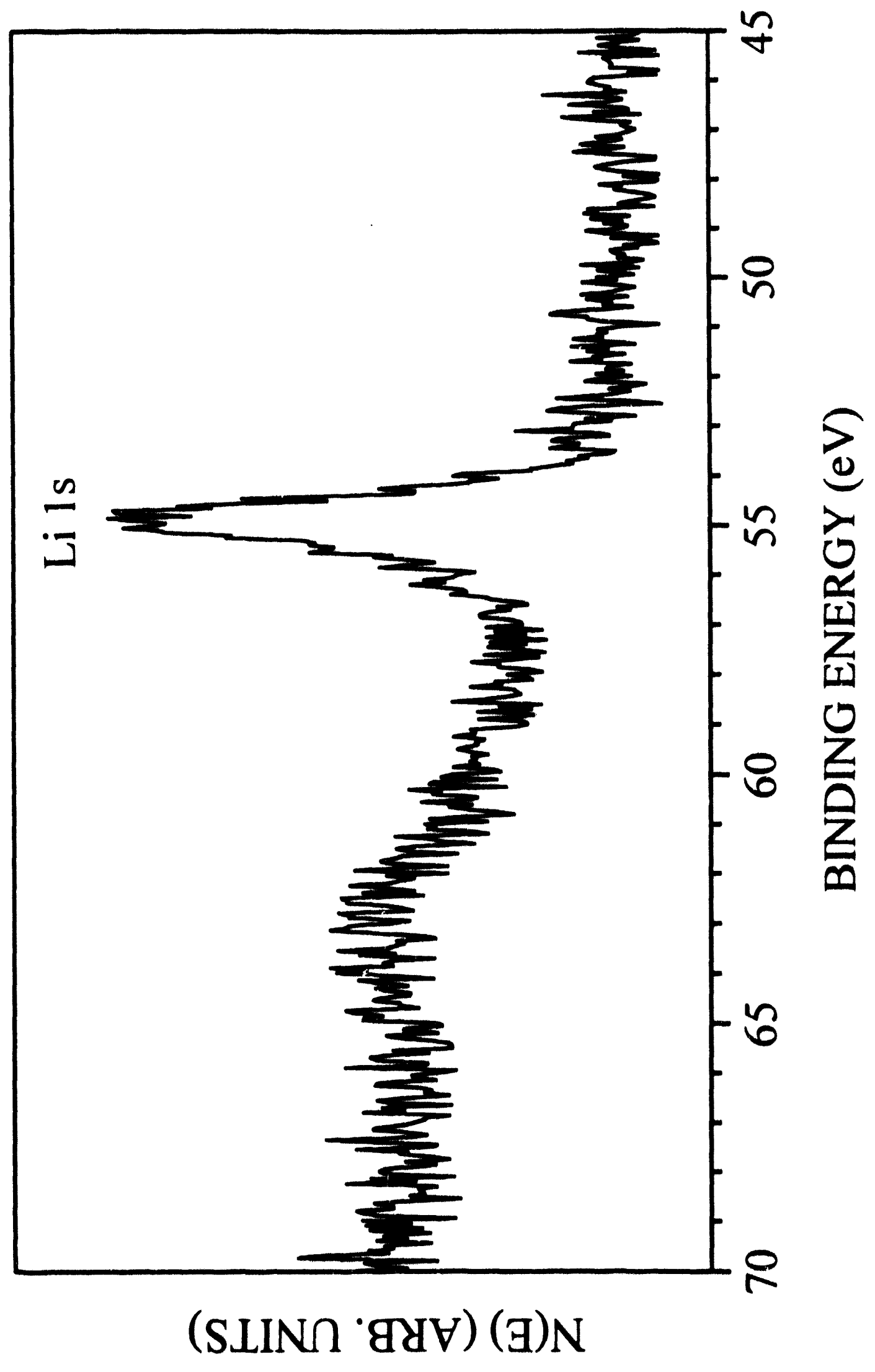

Figure 2 

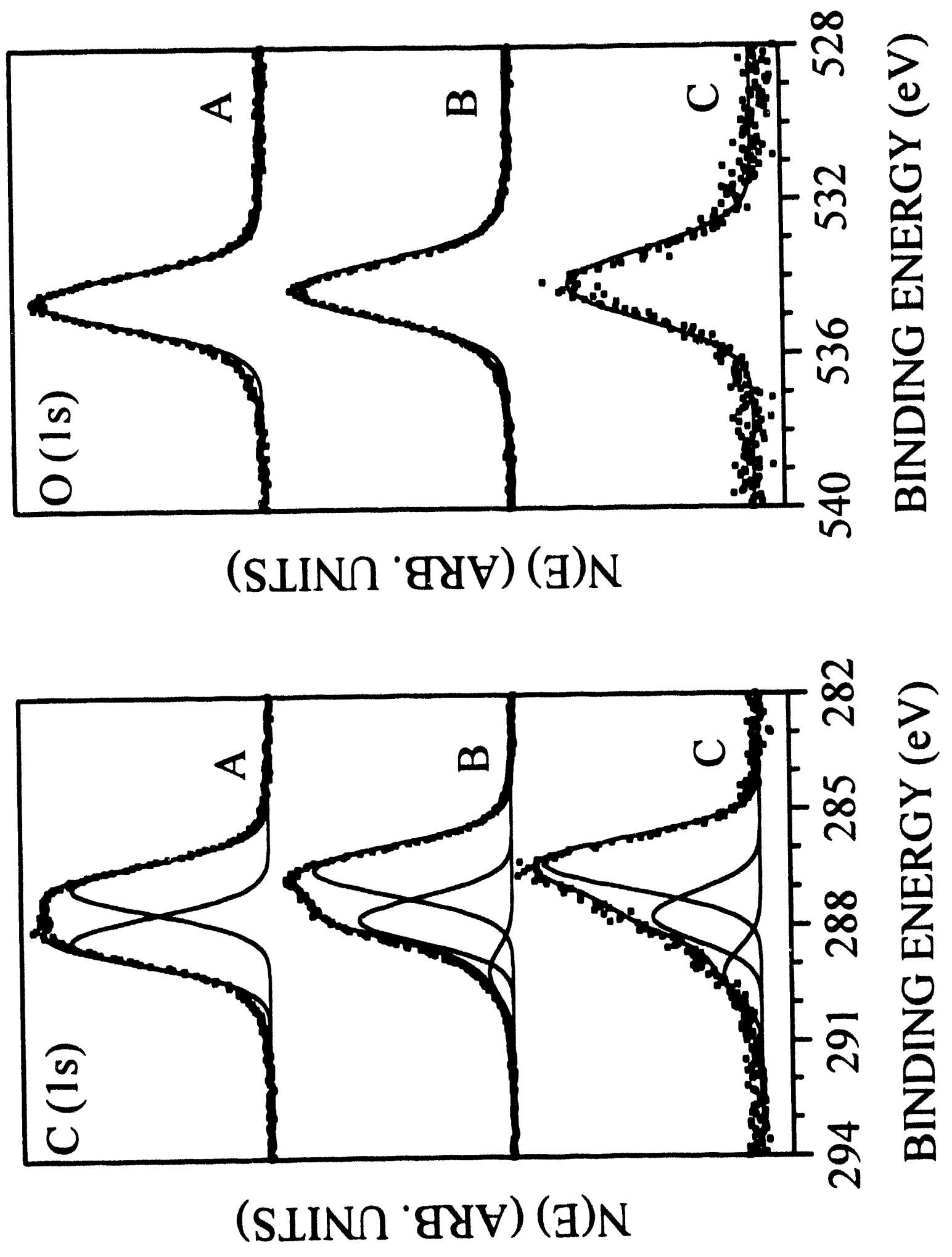

Figure 3 


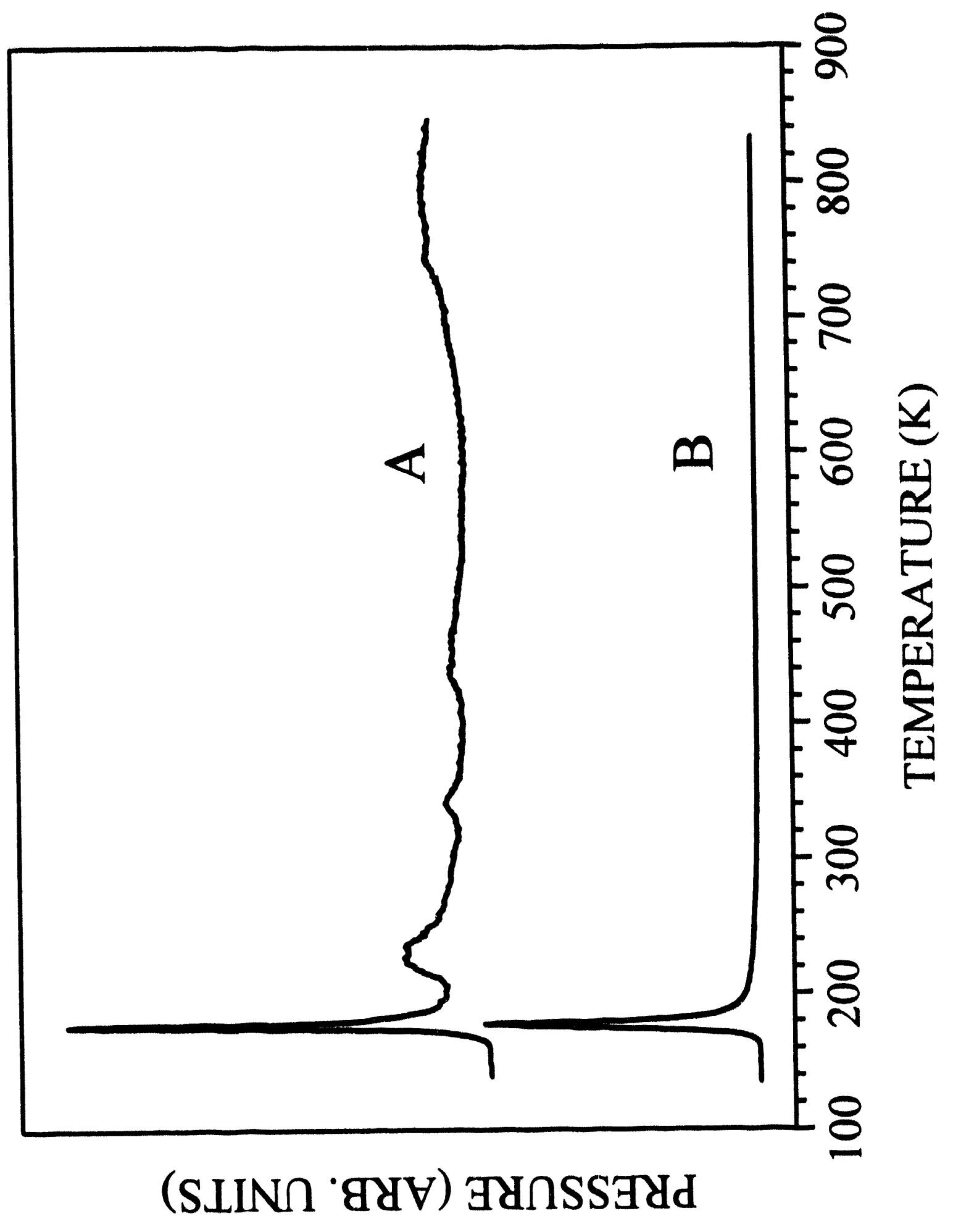

Figure 4 

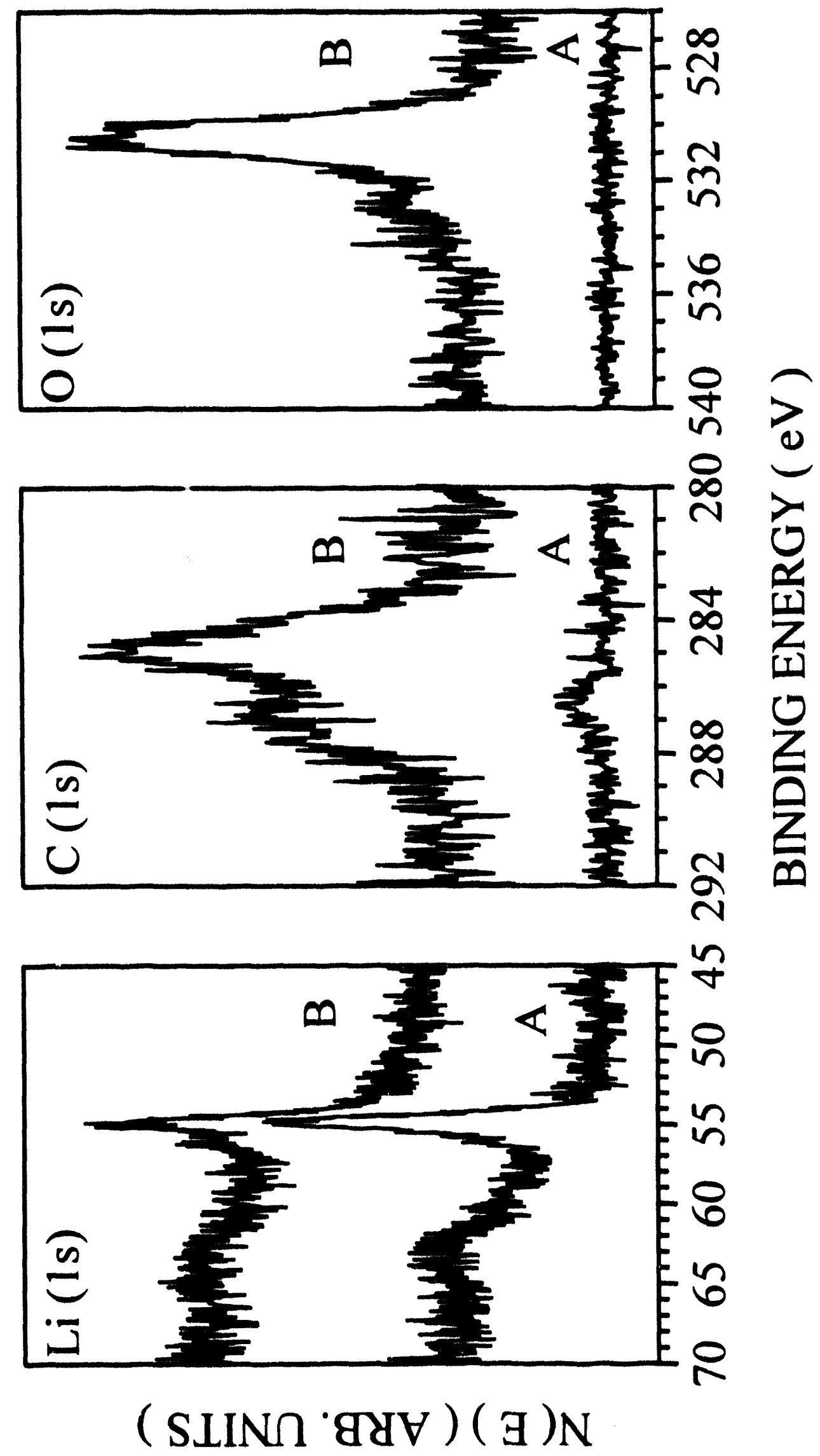

Figure 5 


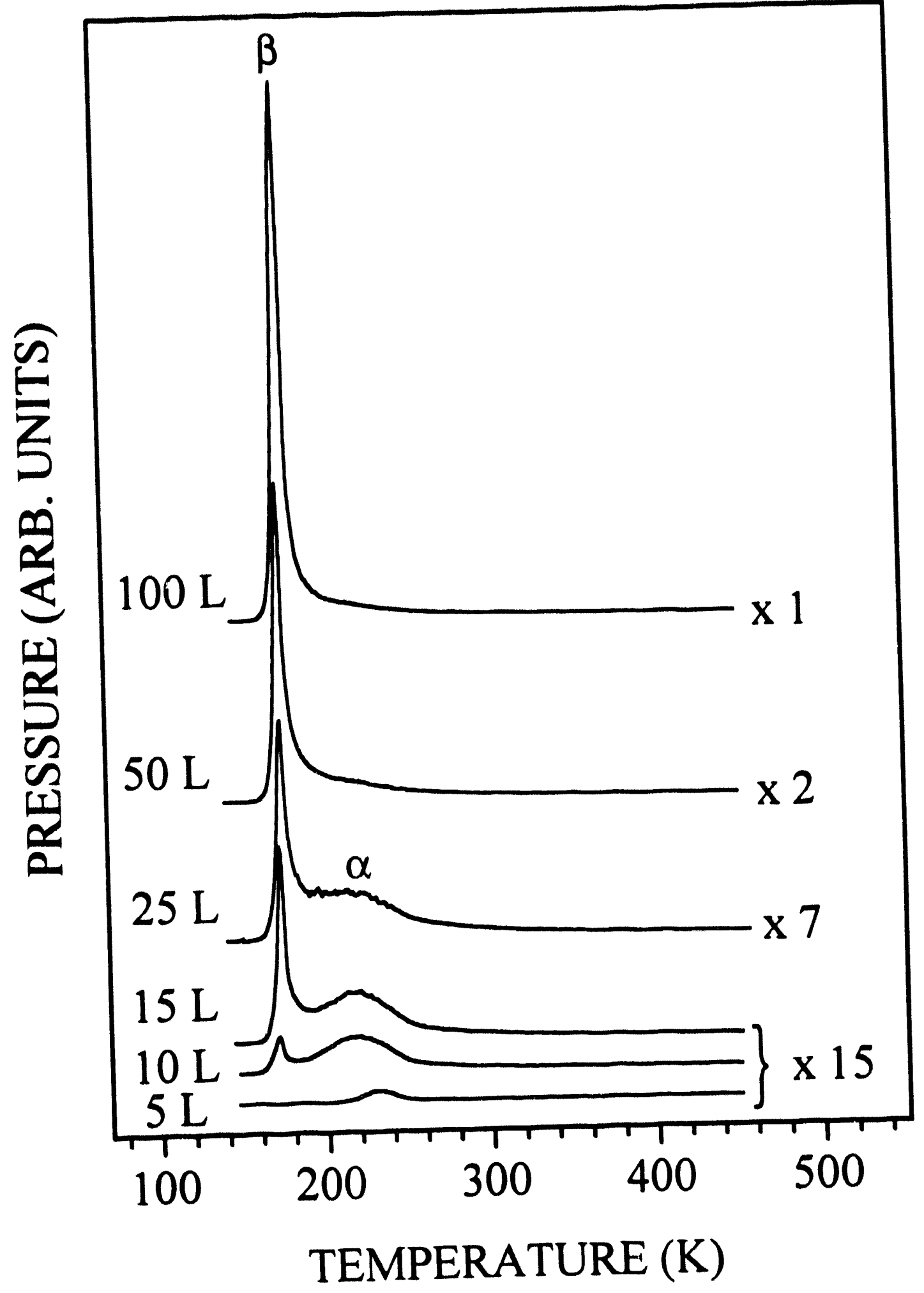

Figure 6 


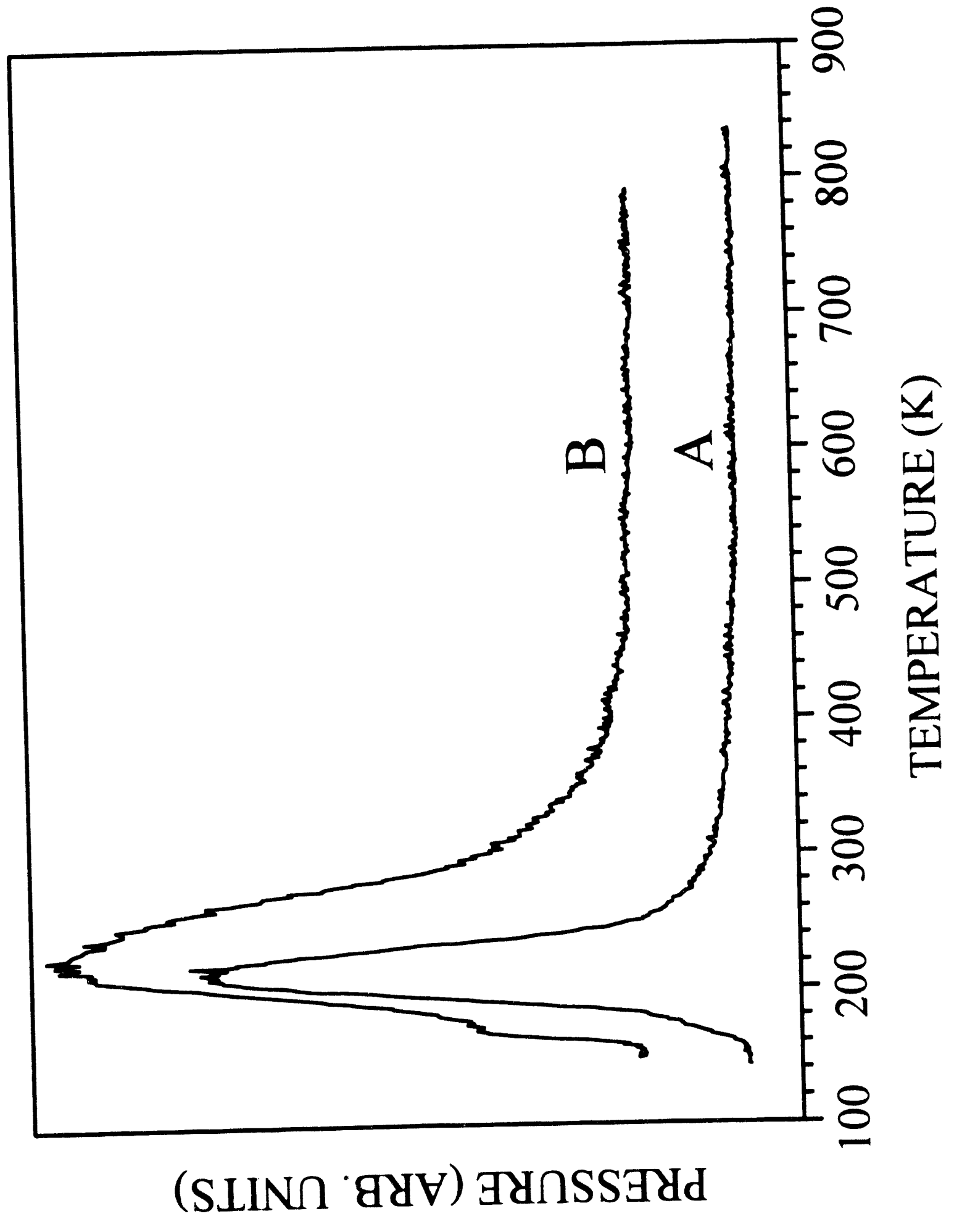

Figure 7 


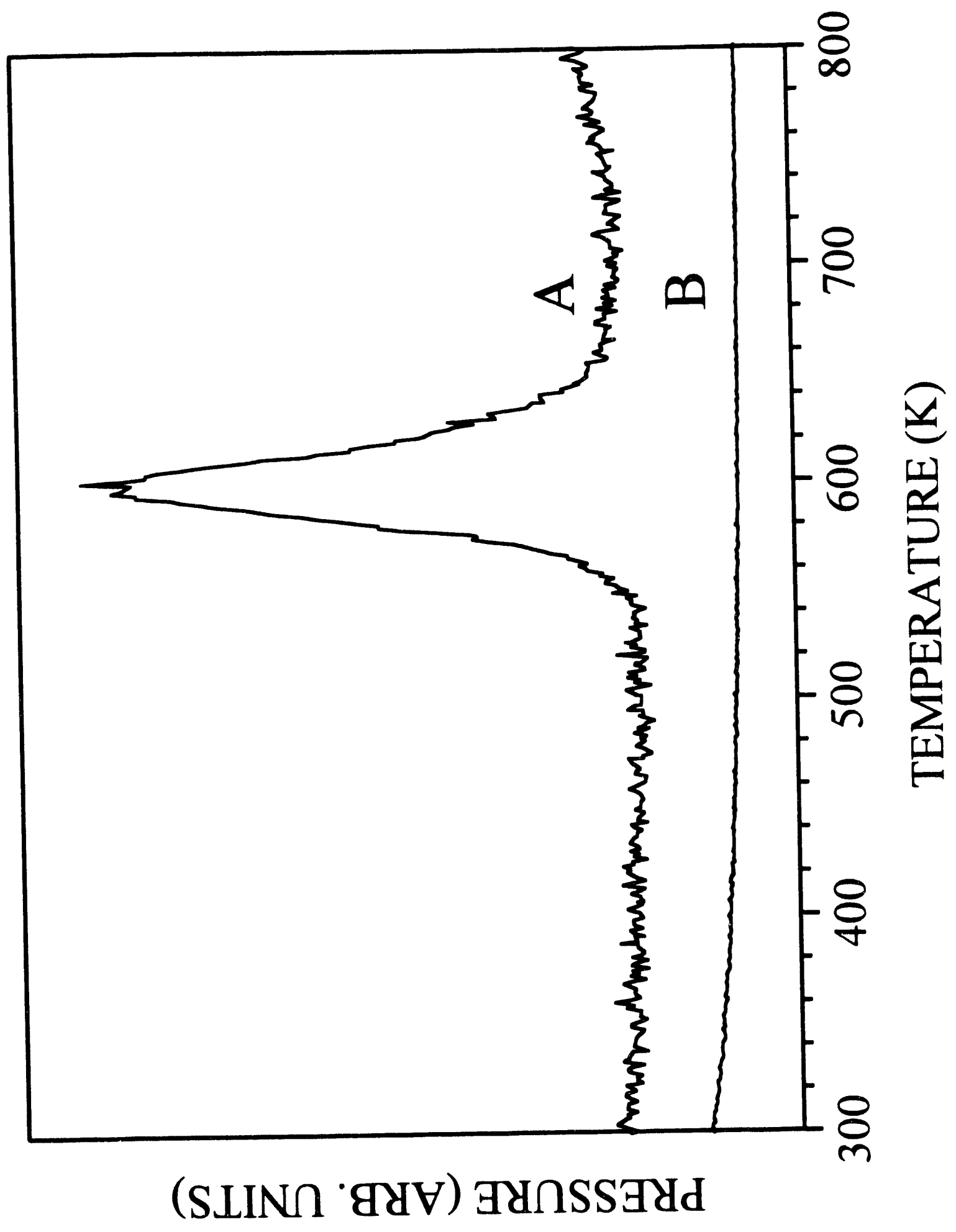

Figure 8 

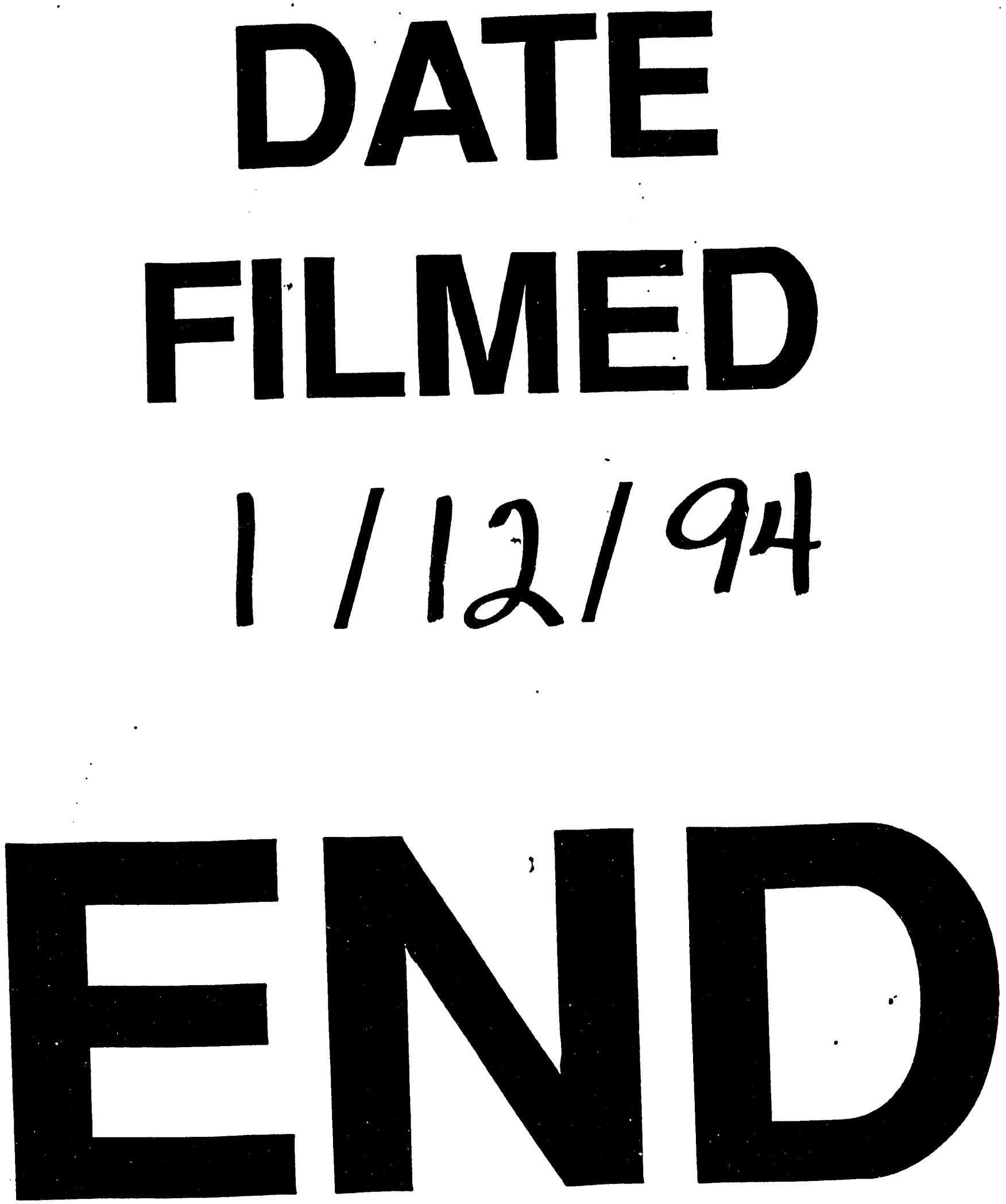
